\title{
A study of spatial water vapor distributions by using one-way residuals of GPS phase measurements
}

\author{
T. Yoshihara ${ }^{1}$, T. Tsuda ${ }^{1}$, and K. Hirahara ${ }^{2}$ \\ ${ }^{1}$ Radio Science Center for Space and Atmosphere, Kyoto University, Kyoto 611-0011, Japan \\ ${ }^{2}$ Department of Earth and Planetary Sciences, Graduate School of Science, Nagoya University, Nagoya 464-8602, Japan
}

(Received June 8, 2000; Revised January 17, 2001; Accepted January 26, 2001)

\begin{abstract}
We investigated water vapor distribution in the troposphere, concentrating especially on meso-scale phenomena, such as a cumulus cloud, with dimension less than about $10 \mathrm{~km}$ in the horizontal direction by using GPS phase signals along their propagation paths. Slant path water vapor can be estimated from the GPS phase residuals obtained by subtracting the theoretical phase value from the observed one. We obtained the residuals as by-products of phase data analysis with the GIPSY-OASIS II software. We analyzed a 11-day campaign data set obtained at Yamagawa $\left(31.2^{\circ} \mathrm{N}, 130.6^{\circ} \mathrm{E}\right)$, Japan in June, 1996. During the observation, four sudden weather condition changes were seen, the passage of a cold front and Baiu fronts. The fluctuation of the residuals is dominated by their dependence on elevation angles of the GPS Satellites rather than the fine variation of water vapor. Thus, we corrected the residuals by subtracting the elevation-angle-dependence, which was obtained by means of the residuals, for each elevation angle over the entire observation period. The water vapor distribution calculated from the corrected residuals showed more realistic features that correspond to frontal structures. However, this correlation occurred only in several cases of changes of weather condition with the passage of fronts. We further obtained good consistency with the corrected residuals even among the different types of antennas which were located within a few meters by using the another data-sets of past campaigns which were carried out on the campus of Nagoya Univ. $\left(35.2^{\circ} \mathrm{N}, 137.0^{\circ} \mathrm{E}\right)$, Japan in October.
\end{abstract}

\section{Introduction}

The Global Positioning System (GPS) is a satellite navigation system, which is widely used by civilians and scientists. A total of 24 GPS satellites in 1996 (currently 28) orbit the earth at an altitude of about $20,000 \mathrm{~km}$ with a period of a half sidereal day. So, we access this system with GPS receivers on or near the earth. Usually dual-frequency receivers are used for scientific applications in order to remove the effects of the ionosphere in the received data.

There are two approaches to the meteorological application of GPS, namely, space-based and ground-based GPS meteorology (Bevis et al., 1992). The space-based GPS meteorology mainly uses the occultation technique to estimate a temperature profile in the stratosphere from the propagation delay of the GPS signals received from the low earth orbiting (LEO) satellites, which go around the earth at an altitude of about $500 \mathrm{~km}$. On the other hand, the main target for the ground-based GPS meteorology is water vapor content in the troposphere. The propagation delay of the neutral atmosphere can be separated into dry and wet components (Hopfield et al., 1969). The former, which is called hydrostatic delay, results from the dry atmosphere density and the latter, which is called wet delay, is from the water vapor in the atmosphere. The hydrostatic delay can be accurately determined by combining GPS and surface pressure mea-

Copy right (c) The Society of Geomagnetism and Earth, Planetary and Space Sciences (SGEPSS); The Seismological Society of Japan; The Volcanological Society of Japan; The Geodetic Society of Japan; The Japanese Society for Planetary Sciences. surements (e.g. Duan et al., 1996). However, the wet delay changes greatly with the water vapor content in the troposphere. The wet delay in the zenith direction is related to the precipitable water vapor (PWV) by a proportional constant $\Pi$ of 0.15 in the typical case of an atmospheric weighted mean temperature of $260 \mathrm{~K}$ (Askne and Nordius, 1987). Using this powerful water vapor information, obtained with the nation-wide GPS network of the Geographical Survey Institute (GSI), the (relative) change in water vapor distribution all over Japan was estimated and the passage of a cold front was detected (Iwabuchi et al., 1997).

In the ordinary GPS phase analysis, signals received from the GPS satellites above an elevation angle of $15^{\circ}$ are used. Therefore, PWV from these analyses represent the average value of the reverse cone. However, a better spatial resolution is expected using slant wet delay, which is the propagation delay along an actual ray path from GPS satellite to receiver. We know that GPS results of slant wet delays should be consistent with pointed radiometer results in the double difference phase residuals (e.g. Ware et al., 1997; Alber et al., 1997).

Here, we try to estimate slant wet delay from the zenith wet delay and one-way phase residuals. Further, we will give an estimate of the three-dimensional water vapor distribution by combining these many slant wet delays and using a tomography technique in the near future. Although our final purpose is to do a water vapor tomography, as a first step, we examine the accuracy of the slant wet delay. 
In this study, we propose a method to investigate spatial variation of atmospheric water vapor using slant path wet delay determined from one-way residuals of GPS measurements. Here, GIPSY-OASIS II software, which provides residuals for each slant path from GPS satellite to receiver, was used for data analysis. There are two important problems to discuss.

First, these one-way residuals seem to be strongly contaminated with multipath effects (e.g. Elósegui et al., 1995) and antenna phase characteristics (e.g. Tsuji et al., 1993; Imakiire et al., 1997). In Section 3, we investigated means to remove such noise from the residuals. We tried to correct these effects on the one-way residuals.

Second, the corrected residuals had to be examined as to whether or not they reflected actual distributions of atmospheric water vapor. In Section 4, several cases were studied in which we compared the residuals with other observations especially during the occurrence of meteorological events such as the passage of fronts. We also obtained good consistency with the corrected residuals even among the different types of antennas which were located within a few meters.

\section{GPS Observational Data}

2.1 Coordinated measurements in Yamagawa during a Baiu front activity in 1996

Coordinated observations, called TREX (Torrential Rain EXperiment), were carried out in the south Kyushu area of Japan, during June and August of 1996, in order to study meteorological disturbances associated with a Baiu front. Seven research groups from universities and national research institutes participated in the campaign, operating a variety of in-situ and remote-sensing equipment, such as a balloon-borne radiosonde, a meteorological Doppler radar, a dropsonde released from an aircraft, a Boundary Layer Radar (BLR), and so on. The Radio Atmospheric Science Center (RASC) of Kyoto University joined the experiment at the Yamagawa Radio Observatory $\left(31.2^{\circ} \mathrm{N}, 130.6^{\circ} \mathrm{E}\right)$ of the Communications Research Laboratory (CRL), Ministry of Posts and Telecommunications, in collaboration with CRL and Kagoshima University. The location of the Yamagawa Radio Observatory is shown in Fig. 1. We continuously operated a BLR and a ceilometer at the observatory, and launched a radiosonde at intervals of 3-24 hours during a disturbed weather event.

We installed three GPS receivers (receiver type: Ashtech Z-XII3) June 13-25 both within and outside the observatory in order to study the distribution of water vapor within a few hundred meters of the observatory. These receivers were located over a total distance of about $900 \mathrm{~m}$ and aligned in a nearly west-east direction. CENT, which was the station name, was set up on the roof of the observatory building.

We employed a balloon-borne radiosonde (VAISALA RS-80-15N), consisting of a barometer, thermometer and a hydrometer. The horizontal location of the radiosonde was determined using a VLF radio navigation system. Then, the horizontal motion of the rawindsonde, i.e. horizontal winds, was derived from the time derivative of the horizontal position giving us the wind speed. During a meteorologically disturbed condition, we launched radiosondes from the Yamagawa observatory at irregular intervals. In particular, a

\section{Campaign Stations in Yamagawa and Nagoya}

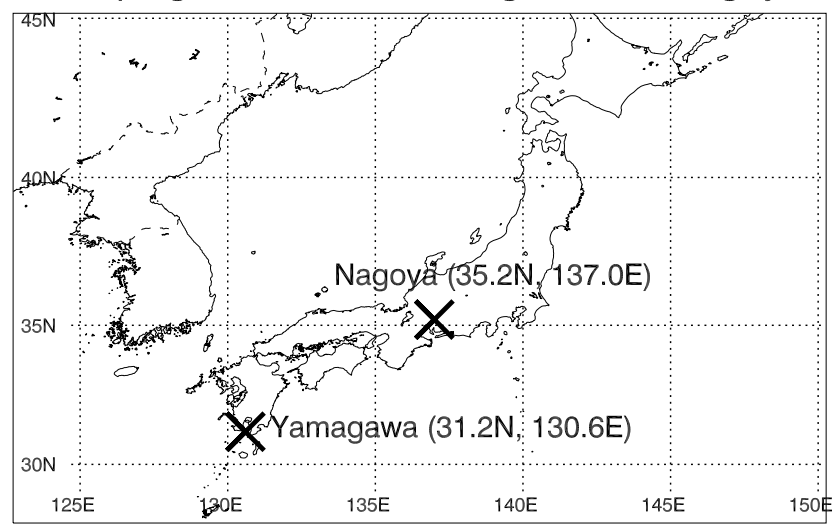

Fig. 1. Locations of the Yamagawa Radio Observatory and the campus of Nagoya University in Japan.

total of 19 rawindsondes were launched on June 15-25 when the GPS receivers were operated. We estimated PWV from the rawindsonde data by using the trapezoid formula. The proportion constant, $\Pi$, was estimated as an averaged value of 0.1635 from the profiles of temperature, humidity and pressure provided by 17 radiosondes launched during the entire period except two radiosonde which presented unusual profiles.

We also installed a laser-ceilometer (VAISALA CT 12K) to determine the distribution of clouds, which we thought would be very useful for a study of the relation between small-scale water vapor variations and clouds in the atmospheric boundary layer. A ceilometer transmits a laser pulse, and receives scattered information from cloud particles with a telescope. It can detect the existence of clouds, together with the distance to the scatterers with a height resolution of $15 \mathrm{~m}$. During the GPS campaign, we pointed the ceilometer in the zenith direction, so as to measure the height distribution of clouds. This ceilometer is capable of detecting the bottom height and thickness of the lowest two cloud layers, below 3,800 m, with a sampling interval of $12 \mathrm{sec}$.

CRL developed a BLR with an operating frequency of 1357.5 MHz, and transported it to the Yamagawa observatory during the TREX campaign. BLR detects radio waves scattered by clear-air turbulence, at $0.3-3 \mathrm{~km}$, and also detects echoes from rain drops. The echo intensity, radial wind velocity and spectral width was recorded every $5 \mathrm{~min}$. with a height resolution of $75 \mathrm{~m}$. A parabolic antenna was mechanically oriented to the vertical position with two oblique beams with a zenith angle of $10^{\circ}$ aligned to the east and north, respectively, with a time interval for one cycle of 5 min. Combining these radial winds, we inferred zonal and meridional winds.

These instruments were located close to each other, within about $30 \mathrm{~m}$ radius of the CENT station. The detailed periods of obtained data for the above measurements are shown in Fig. 2.

For the surface meteorological data, i.e. surface pressure, temperature, precipitation, etc., we referred to the hourly data obtained at the Kagoshima meteorological observatory, located about $40 \mathrm{~km}$ north-northwest of the Yamagawa ob- 


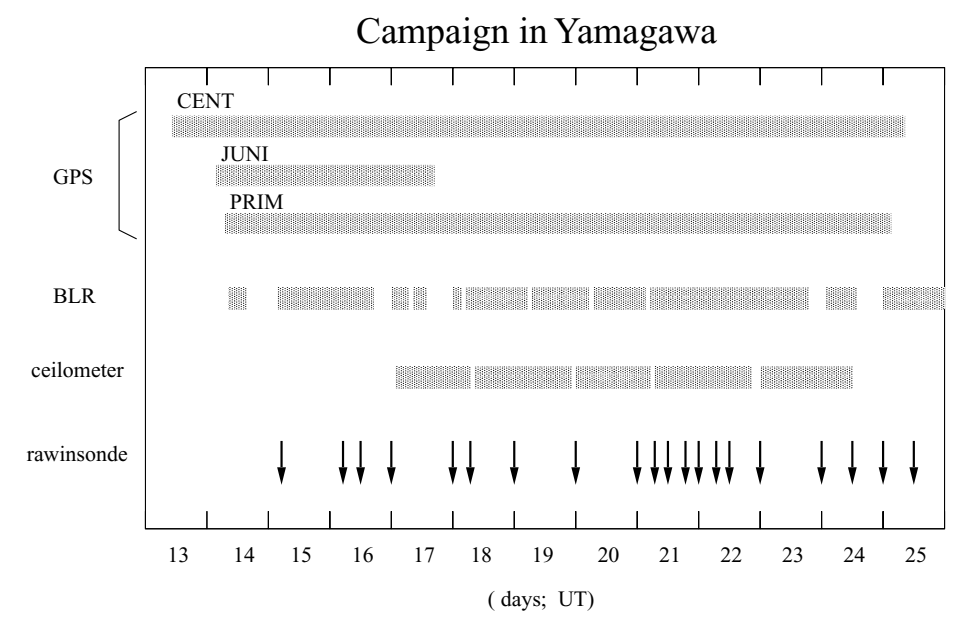

Fig. 2. Observation period for each measurement during the Yamagawa campaign on June 13-25, 1996.

servatory. We also referred to satellite observation by GMS5, which provided cloud distributions above Japan with pictures using infrared and visible rays, in order to obtain the weather conditions above the observation site.

During this campaign period, the weather conditions changed greatly with the motion of a cold front, which passed from the north-west to the south-east, and a Baiu front, which swung in the north-south direction above Yamagawa.

\subsection{A GPS campaign on the campus of Nagoya Univer- sity for tomography of water vapor}

Another GPS campaign was performed October 21-25, 1997, with 12 GPS receivers on the campus of Nagoya University $\left(35.2^{\circ} \mathrm{N}, 137.0^{\circ} \mathrm{E}\right)$, Japan. The location of Nagoya University is shown in Fig. 1. This campaign was conducted by Dr. Kimata of Earth and Planetary Sciences, Graduate School of Science, Nagoya University, and was aimed at obtaining a set of data for a local water vapor tomography with a west-east cross section and with small-scale spatial resolution of approximately a few hundred meters. Figure 3 shows the location of the 12 GPS receivers and other meteorological observation points.

Because weather mainly moves from west to east with a motion of a migratory anti-cyclone (high pressure area) and a cyclone (low pressure area) in this season, a total of 12 GPS receivers were nearly aligned in the west-east direction with all 12 within about $1 \mathrm{~km}$. Generally, there were 10 GPS observation sites, therefore the average distance between neighboring observation sites was about $100 \mathrm{~m}$. Each GPS receiver was installed on the roof of a school building. In this campaign, we used two kinds of antennas, Ashtech Z-XII3 and Trimble 4000SSI. We assigned a four character station name to each GPS receiver with the two characters "NG" in the center. The first character of the station name indicates the site number going from 1 in the west to 10 in the east. The last character in the station name is " $\mathrm{A}$ " or " $\mathrm{T}$ ", corresponding to the antenna type (i.e. Ashtech or Trimble, respectively).

Although there were 12 stations, we specifically refer to 4 special stations, two pairs, 2NGA and 2NGT, and 8NGA and $8 \mathrm{NGT}$, in order to examine the differences in slant wet delay results between the two kinds of antennas. These two pairs, using the two different kinds of antennas, were installed at sites number 2 and 8, which were separated by about $790 \mathrm{~m}$. At both sites, the two receivers were located within a few meters.

For each of the above mentioned two special sites (i.e. sites 2 and 8), we also set up a dual-frequency radiometer in the neighborhood of the GPS receivers. In this campaign, we used two types of radiometers (WVR; Radiometrics WVR1000 and WVR-1100), which were programmed to point in 11 directions between $5^{\circ}$ and $170^{\circ}$ along an east-west direction and to measure wet delay in each view direction with a time resolution of about $3.5 \mathrm{~min}$. and $1.4 \mathrm{~min}$. at sites 2 and 8, respectively. Therefore, PWV (i.e. the result with an elevation angle of $90^{\circ}$ ) were measured about every 38.5 min. and $15 \mathrm{~min}$. at sites 2 and 8, respectively. Sometimes the window of the microwave receiver gets wet due to raindrops, etc. In this situation the WVR estimate includes a significant error.

The surface meteorological data, such as pressure, temperature and humidity, were measured every $10 \mathrm{~min}$. at site number 8 . These surface data were collected throughout the entire campaign period.

A total of 8 radiosondes with a GPS navigation system, which provide vertical profiles of pressure, temperature, humidity and horizontal wind velocity, were launched from site number 8 during the campaign period. However, the air lanes of the air planes which take off and land at the Nagoya Airport (located about $12 \mathrm{~km}$ north-northwest of the campus) were above the sonde launching point. Therefore, the GPS sondes were launched only at around midnight (13-20 UT), because many airplanes passed overhead, especially in the daytime.

Here, we briefly refer to the weather condition and the data actually obtained during the campaign period. In the period from October 21 to 23, it was very clear, so much so that, in spite of our expectations, there were no clouds. However, a cold front passed above Nagoya accompanied by a small quantity of rainfall around 15 UT on October 24. Therefore, we mainly carried out the observation in the latter half of the October 21 to 25 time period rather than in 


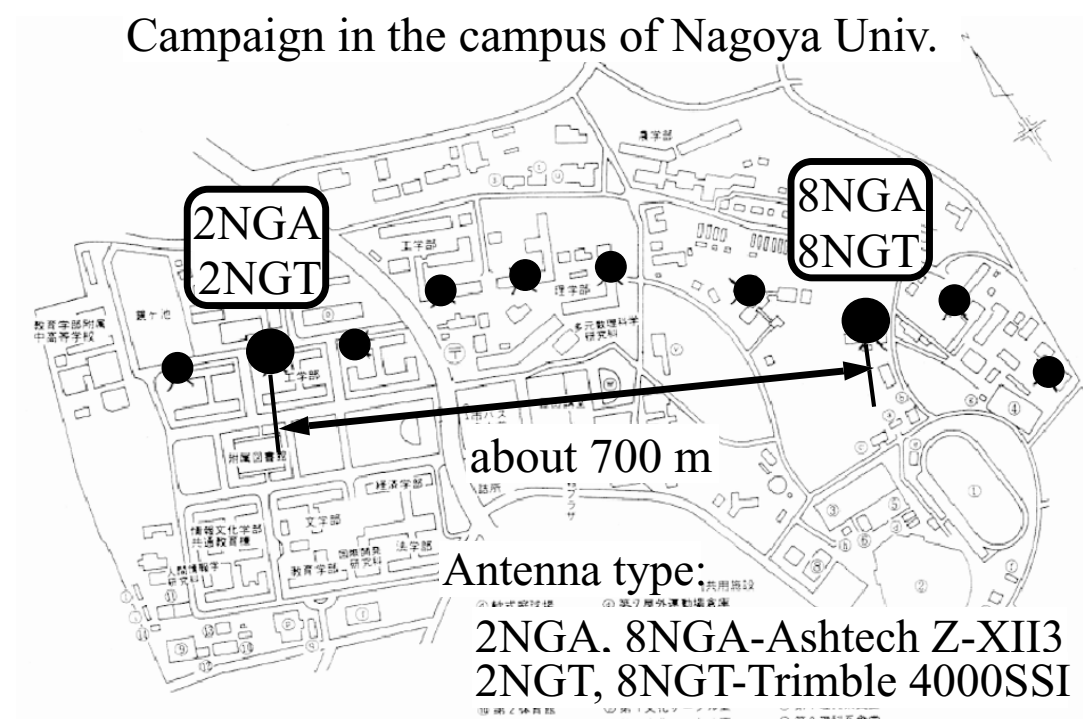

Fig. 3. Total of 12 GPS receivers were located nearly along a straight west-east line in the campus of Nagoya University, Japan. Two pairs of two receivers, one pair designated 2NGA and 2NGT and the other pair designated 8NGA and 8NGT, were located close to each other at the western and eastern site, respectively.

the first half. Especially on October 23 and 24, all 12 GPS stations were programmed to operate and the radiosonde observations were performed during 11-23 UT. The four special stations (2NGA and 2NGT, and 8NGA and 8NGT) and the two radiometers were operated almost continuously throughout the campaign period. More detailed information of these observational periods is shown in Fig. 4.

\section{Data Processing}

\subsection{The primary analysis for GPS data processing}

In this study, we used the GIPSY-OASIS II software for analysis of the observed GPS data, because it can provide one-way phase residuals as a by-product. The major error sources of ground-based GPS data processing, are satellite orbit error, satellite clock error, receiver clock error, tropospheric delay, multipath effects and antenna phase variation. Satellite orbits have recently been determined to within a few centimeters by using the combination analysis with the global IGS (International GPS Service for Geodynamics) stations. Satellite clock errors have also been estimated with a time resolution of $5 \mathrm{~min}$. by using global IGS stations together with satellite precise orbit information from the JPL (Jet Propulsion Laboratory). The receiver clock errors and the tropospheric delay are time-dependent parameters and can be estimated by using a receiver positioning analysis of GIPSY. The post-fit residuals were calculated by subtracting the reconstructed carrier phase, which was computed by using the estimated results of a receiver position and timedependent parameters (i.e. receiver clock error and tropospheric propagation delay in the zenith direction), from the observed phase. Because of the limitation imposed by the satellite clock errors with an interval of 5 min., we selected the estimation interval of time-dependent parameters as 5 min. Therefore, post-fit residuals were obtained for each (visible) satellite with a time resolution of $5 \mathrm{~min}$. In this study, we treated residuals which were greater than $5 \mathrm{~cm}$ as abnormal and we did not use such phase data for the anal- ysis. In the GIPSY, we can also estimate a parameter for a horizontal gradient on tropospheric delay. However, we estimated no gradient because we would expect that these effects could be contained in post-fit residuals.

Although the effects of the following noise sources were contained in residuals, we were very interested in differences in phase delay among the GPS satellites, which we could usually find in more than 4 directions, because of inhomogeneous distribution of water vapor. Therefore, residuals can represent differences from (spatial averaged) wet delay and we can reconstruct the distribution of water vapor by using this information.

\subsection{Post-fit residual}

Here, we discuss the general characteristics of the residuals obtained through the above-mentioned analysis. It is known that the antenna phase variation and the multipath effects of the aforesaid major error sources often produce significant errors in the vertical component of position and tropospheric delay by changing the elevation cut-off angle of the GPS satellites (e.g. Meertens et al., 1996). Therefore, we suspect that these effects considerably influence the results of residuals, especially in their elevation-angle-dependence.

Figure 5 shows post-fit residuals obtained directly from GIPSY-OASIS II analysis for the data on June 14, 15 and 16 in 1996. We can see that wet delay is contained in them by comparing the differences in detailed dispersions among the results for the three days. However, the fluctuation of the residuals is dominated by their dependence on elevation angles of GPS satellites rather than the fine variation of water vapor. We can also recognize that the dependence appears every day.

To reduce these effects on residuals, we expected to import an antenna phase variation table for specific elevation intervals and azimuth angles for each type antenna. However, such a table should be measured in advance. Although such a table was introduced to data processing, there were 
The period of obtained data for the campaign in Nagoya Univ.

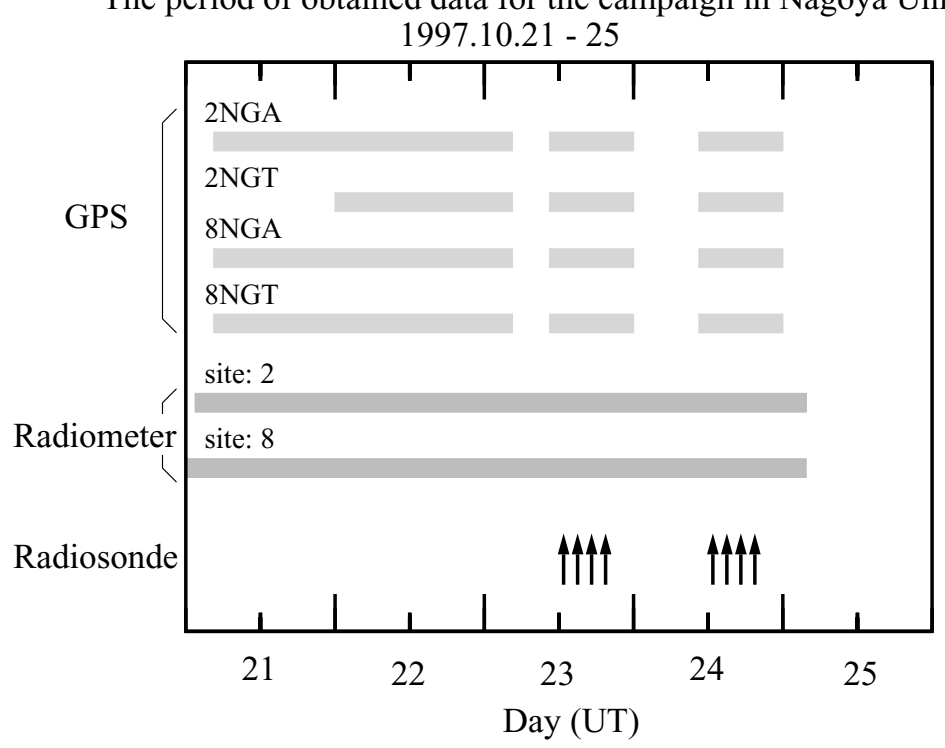

Fig. 4. The period of obtained data for each measurement of the campaign in Nagoya.

still two problems, the differences of antenna phase variation among the same type receivers and the multipath effect variation due to differences in the receiving environment for radio waves among the observational sites. In the other words, each station has these differences and the two effects cannot be separated, but they can be treated as the same effect. Therefore, we developed a new method which estimates the combined contributions of antenna phase variation and multipath effects from residuals.

In this study, we corrected for the discrepancy between a mechanical center and an electrical one for L1 and L2 band carrier phase only by using the phase center correction data. Our correction is based on an investigation of the characteristics of these noise sources (i.e. antenna phase variation and multipath effects). Therefore, we expected that these effects would be directly contained in residuals provided from GIPSY. The effect of our correction is to separate out and extract the meteorological information.

\subsection{Correction for extracting water vapor fluctuations from residual}

Here, we discuss the method to correct residuals by removing the above-mentioned effects from them. The effects of multipath and antenna phase characteristics vary with location of the GPS satellite. In the other words, these effects generally depend on the direction of radio waves incident from the GPS satellite. In the view of the receiver, each satellite moves along its regular route in the sky and repeats this movement $4 \mathrm{~min}$. earlier every day. Therefore, these effects, which are included in residuals, can be represented as a function of elevation and azimuth angles. It is very difficult to estimate the above-mentioned effects from meteorological signals by using such data from only one day. However, these meteorological signals can be regarded as a data set of random signals. Therefore, we can estimate a elevationazimuth-dependence function by calculating the mean value for each direction of each GPS satellite. This results in 24elevation-azimuth-dependent functions, because of the need to calculate for all 24 satellites.

Figure 6 shows 11-day residuals for satellite, Satellite Vehicle (SV), number 39. In this study, we dealt with tracking a satellite as a function of elevation angles and in plotting the residuals as a function of elevation angle we distinguished two states, which were the rising phase of the satellite and the setting one. Therefore, the effects of azimuth angle were integrated into this figure although azimuth angles did not appear there. Note that values of these residuals were projected in the zenith direction and that all of the following residuals were displayed in the same way. In this figure, the averaged-curve shows small-scale perturbations which appear every day and are not random noises. Note that these results were calculated by the interpolation method on elevation angles for each day. Therefore, there is some loss of residual data through the data processing around an elevation angle of 90 degrees.

As the second step, we separately applied this technique to every GPS satellite. Figure 7 represents a comparison of the elevation-angle dependencies of all the satellites. It is interesting to note that in Fig. 7, the averaged values of residuals is strongly reduced near the elevation angle of 90 degrees. As a reference, we also plotted the same results along the regular route of each GPS satellite in the sky (Fig. 8). From this figure, the values of averaged residuals decline near the zenith direction and are similar to other results from different satellites which pass near some of the same regions (e.g. at the area with elevation angle of about $45^{\circ}$ to northeast direction).

We thought that these residuals obtained by the averaging method were caused by multipath and antenna characteristics and we corrected the residuals by subtracting these elevation-and-azimuth-angle dependencies.

\section{Verifications of the Corrected Residual}

In the previous section, we proposed a method to correct the one-way residuals which dominated antenna phase vari- 
Plotting Res. for CENT

96JUN14 (GPS39)
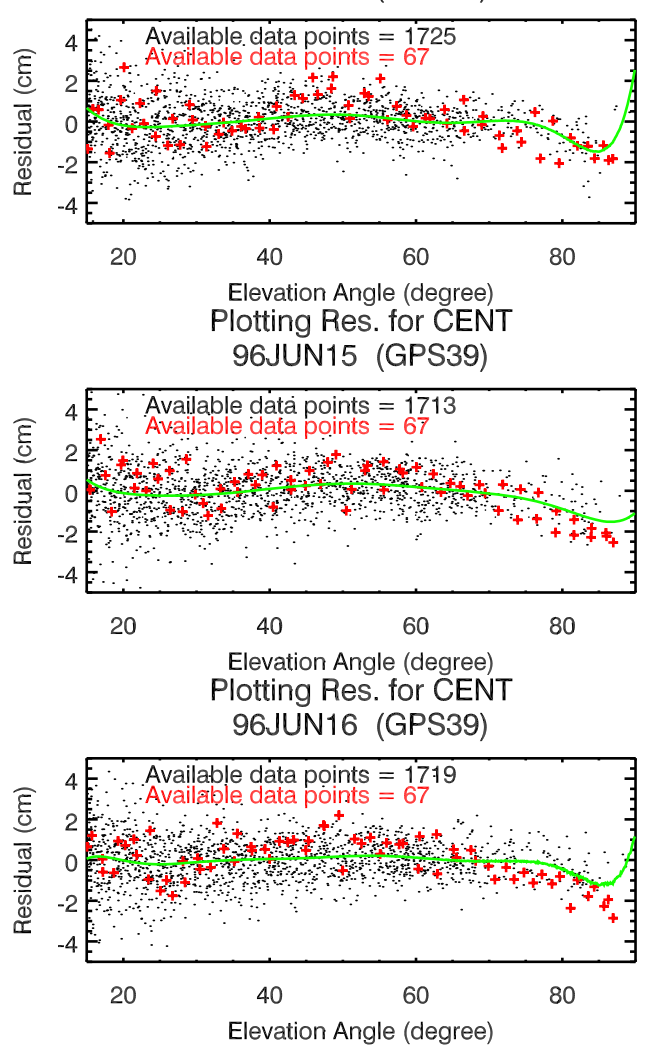

Fig. 5. Post-fit residuals obtained from data from the CENT station through GIPSY-OASIS II every $5 \mathrm{~min}$. plotted with a dot for elevation angles of GPS satellites on June 14 (the top panel), 15 (the middle panel) and 16 (the bottom panel), 1996. A red symbol of (+) represents the residual only for the satellite, Satellite Vehicle (SV), number 39. The green curves represent results of the polynomial fitting.

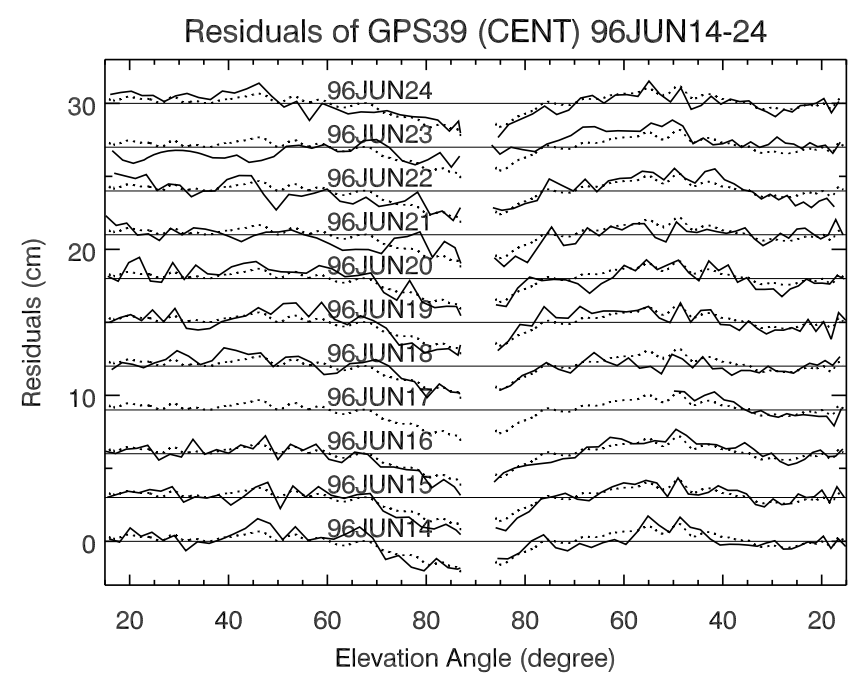

Fig. 6. Comparison between the value averaged for each elevation angle by using 11-day residuals from the SV-39 satellite (dotted line) and the original residuals for each day (solid line). Because the residuals were obtained with a time resolution of $5 \mathrm{~min}$. and the elevation angles were different each day, we interpolated between observational data of the elevation angles for the calculation of the 11-day-mean residual curve. Note that all the plots were projected in the zenith direction with a sine function using the elevation angle of the satellite.

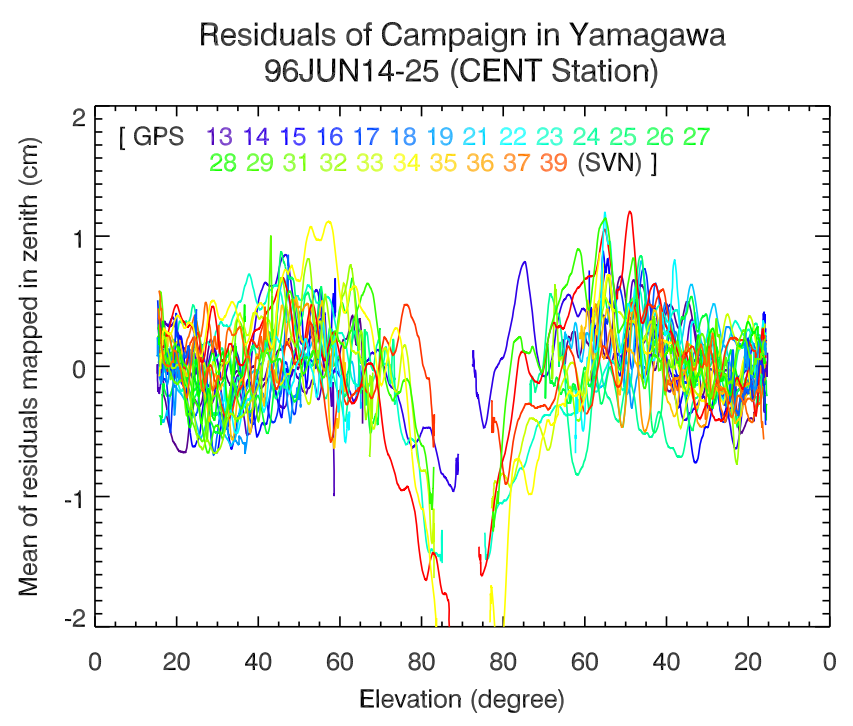

Fig. 7. Comparison of the elevation-angle dependence of all GPS satellites. These results were determined by the same technique as in Fig. 6 .

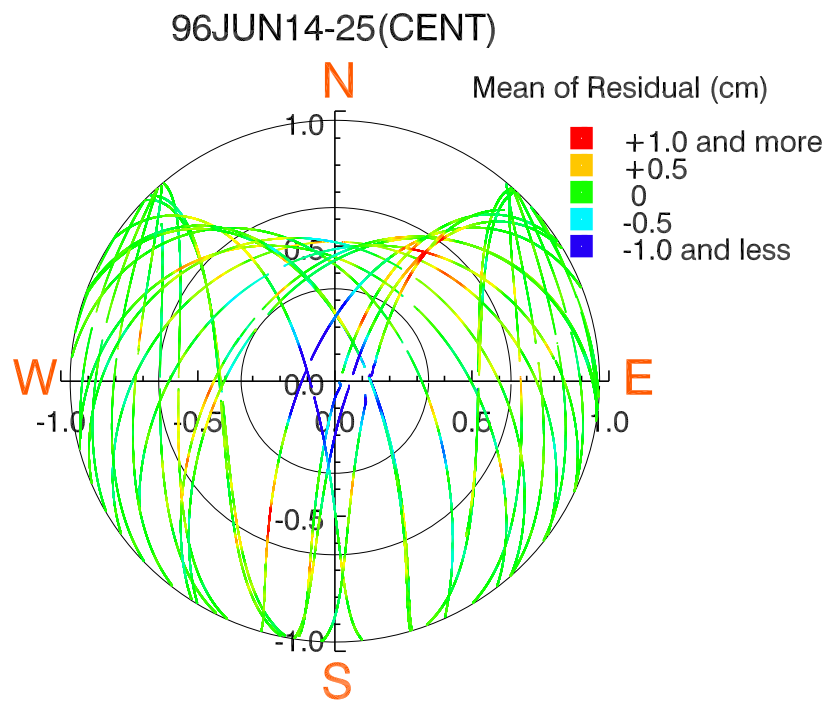

Fig. 8. The same results shown in Fig. 7 were plotted for the regular route of each GPS satellite in the sky. Note that the elevation angles of GPS satellites are represented as projected onto a plane with a cosine function.

ations and multipath effects. In this section, in order to verify whether these corrected residuals reflect actual water vapor distributions, we mainly investigated the following three matters.

1) We examined whether they detected abrupt changes due to a front passage.

2) We compared the corrected residuals with a ceilometer measurement. The ceilometer observed the lower clouds and can detect smaller-scale phenomena. So, we can verify the corrected residuals even in smaller scale changes.

3) We further investigated the consistency of the corrected residuals with GPS receivers located nearby. In such 
a situation, we expected to obtain similar results from the different receivers, even if the antenna types were different.

\subsection{Frontal event}

During the period of the campaign in Yamagawa, a cold front passed once and a Baiu front three times swung above the observation site either from the north to the south or the south to the north. Figure 9 shows a change of PWV during the campaign period. In this figure, these four meteorological events were presented as sudden PWV changes (e.g. at 0 UT on June 18). We tried to verify whether the GPS results showed the fine structure of these four frontal events using the corrected residuals. We obtained results that indicated our expectations in two cases, one were the cold front passed around 0 UT on 18 June, and the other when a Baiu

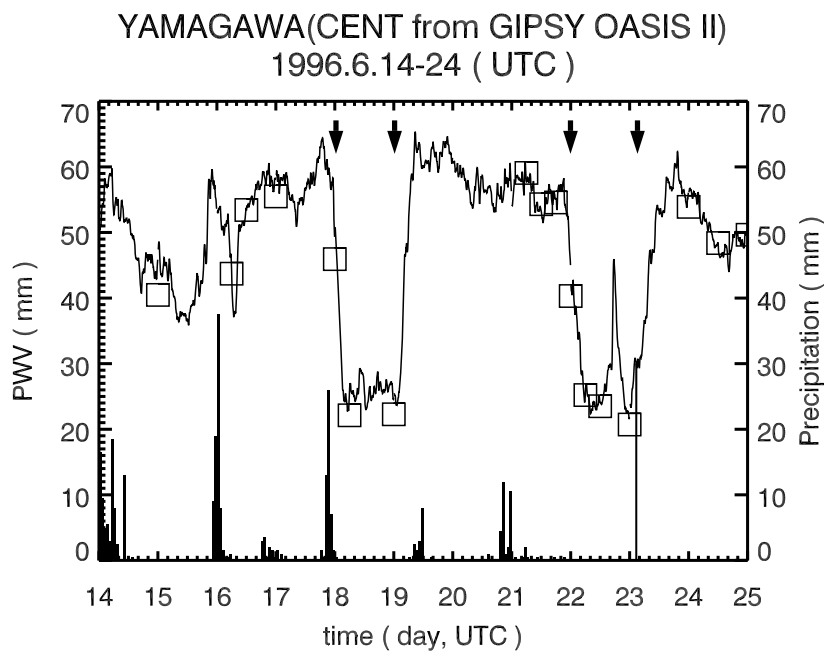

Fig. 9. A solid line shows PWV which was estimated every 5 min. during the period of the Yamagawa campaign. Squares represent radiosonde results. Hourly surface precipitation at Kagoshima (about $40 \mathrm{~km}$ away from Yamagawa) is also plotted in units of $\mathrm{mm}$ (column). Four arrows represent periods of the fronts passages.

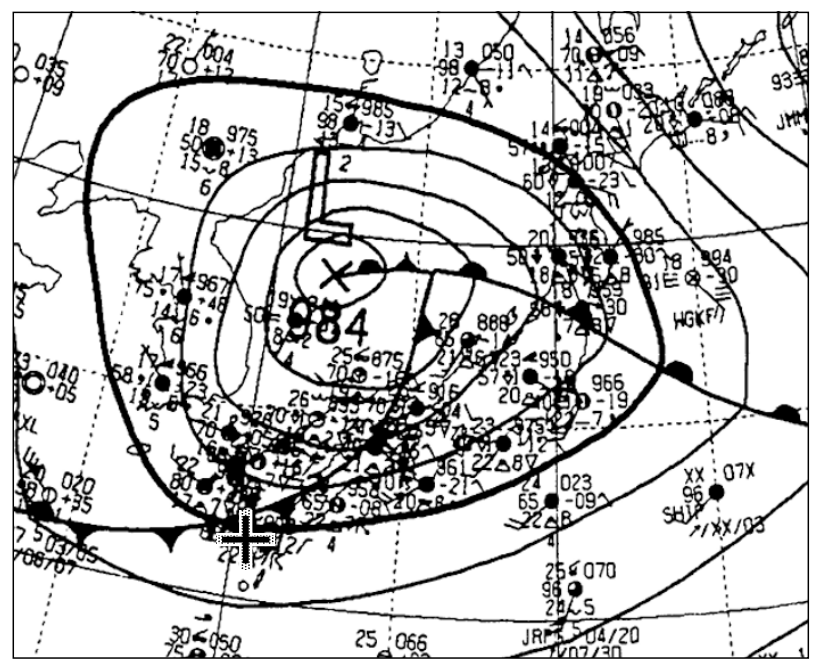

Fig. 10. Surface weather chart around Japan at 0:00 UT on June 18, 1996. A cross mark represents observation site. front passed from the north to the south of the observation site around 2 UT on June 23.

\subsection{Passages of the cold front}

First, we investigated the corrected residuals around the former period. Figures 10 and 11 show a surface weather chart at 0:00 UT on June 18, 1996 and an infrared cloud image observed with the Japanese weather satellite GMS5 at 23:39 UT on June 17, 1996, respectively. Based on a review of a series of surface weather charts and the surface meteorological observations, this cold front passed above Yamagawa in a south-east direction with a velocity of about $40 \mathrm{~km} / \mathrm{h}$ at around 0 UT on June 18. This dramatic frontal event was accompanied by a thunder-storm. In this event, we selected the period from 20 to 24 UT on June 17 to investigate the corrected residuals because of Fig. 11, which showed that a band of developed cumulus clouds had already passed to the south side of Yamagawa before 0 UT on June 18, and at a comparative fast velocity.

We plotted the corrected residuals for the period shown in Fig. 12. In this figure, the magnitudes of the corrected residuals are represented by rainbow colors (larger and smaller values correspond to warmer and colder colors, respectively). It is remarkable that values of the corrected residuals were greater on the south side of CENT than on the north. We can also recognize that there is a high-frequencycomponent which is the result of smaller-class phenomena, smaller than the "original" frontal-class ones. This result seems to make the frontal structure of vapors clearly visible to us.

As shown Fig. 13, we also refer to the corrected residuals for the same period on the next day of this passage to emphasize our interpretation of the results. In this period PWV was much smaller (see Fig. 9) than the previous day. The atmospheric condition was stable due to the cold air in the

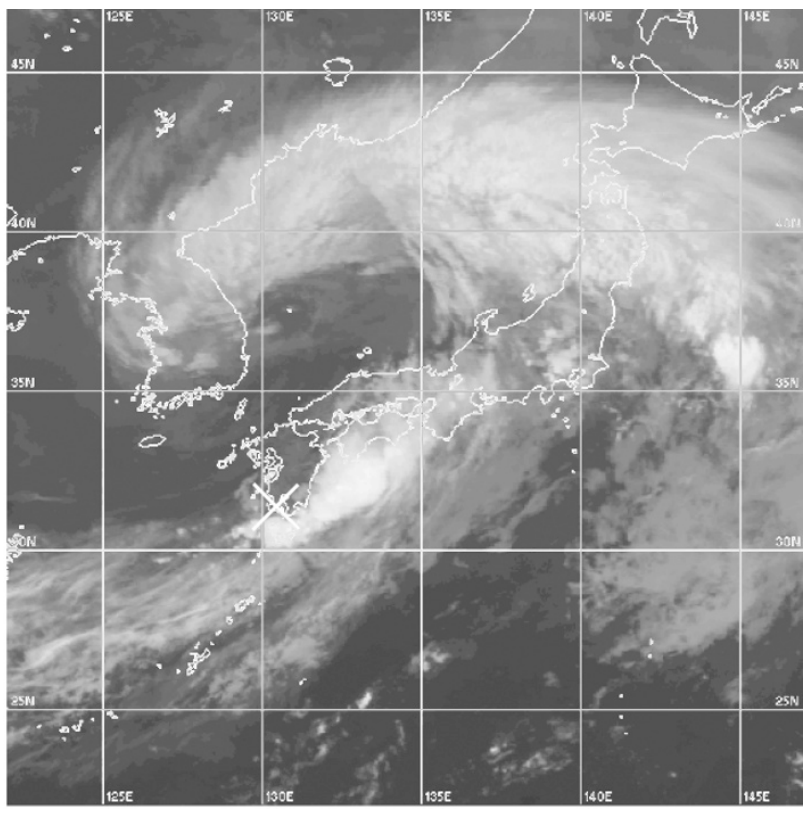

Fig. 11. An infrared cloud image observed with the Japanese weather satellite GMS5 at 23:39 UT on June 17, 1996. A cross mark represents an observation site. 


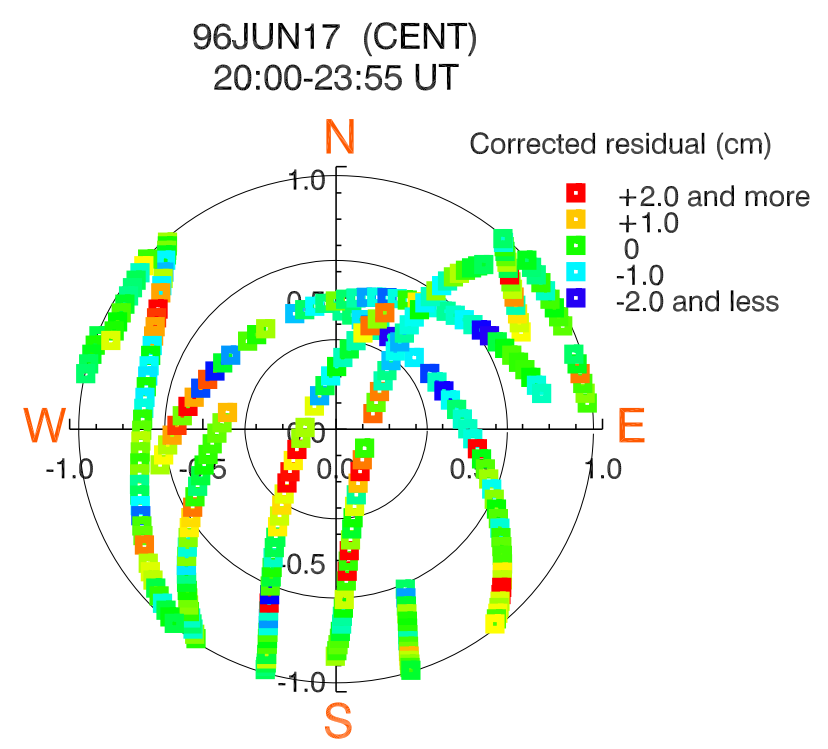

Fig. 12. The corrected residuals are plotted at each position of the GPS satellite during 20 and 24 UT on June 17, 1996. The magnitudes of the corrected residuals are represented by the rainbow colors with the warmer and colder colors corresponding to larger and smaller magnitude, respectively. Note that the elevation angle of the GPS satellite is represented the same as in Fig. 8.

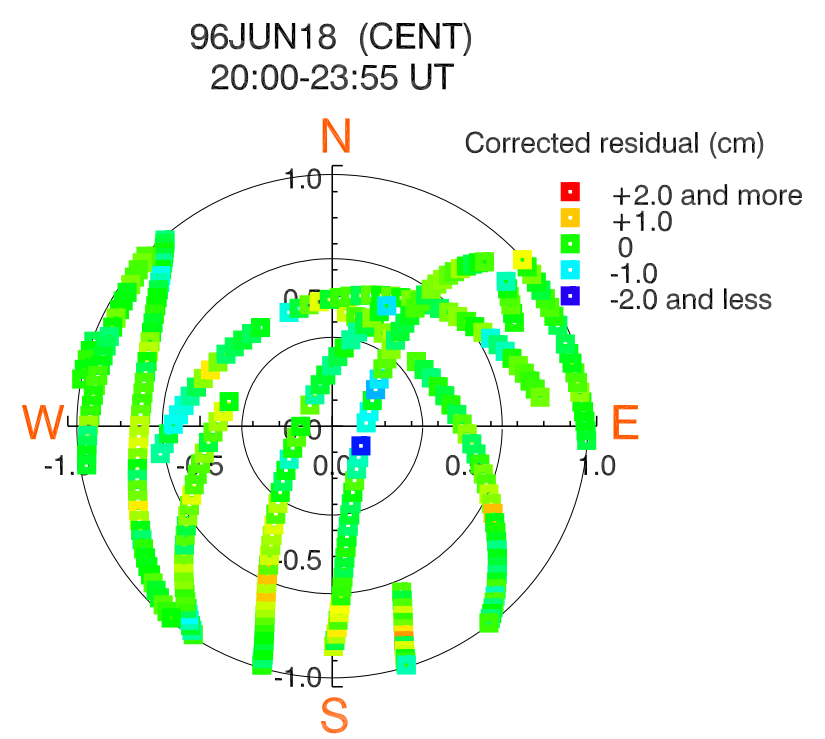

Fig. 13. The same as Fig. 12 except the date is June 18, 1996.

back of the cold front. Therefore, we expected that the atmospheric water vapor would be uniformly distributed. As shown in Fig. 13, the corrected residuals reflected this expectation. Here, to highlight the improvement of the correction, we also show two figures, Figs. 14 and 15. These figures represent non-corrected residuals for the same period as Figs. 12 and 13, respectively. In both Figs. 14 and 15, the elevation-angle dependence of non-corrected residuals was more directly represented rather than the fine structure of water vapor, especially for large elevations as shown in Fig. 15. Thus, we see that this correction method was very useful for eliminating elevation-azimuth dependent noise of

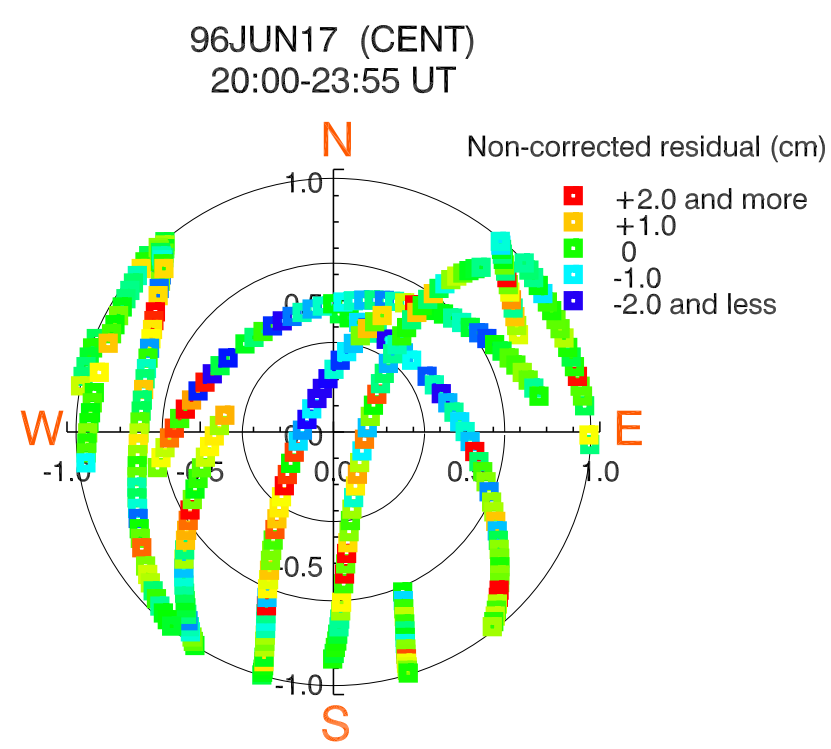

Fig. 14. The same as Fig. 12 except that the non-corrected residuals are plotted.

\section{JUN18 (CENT) 20:00-23:55 UT}

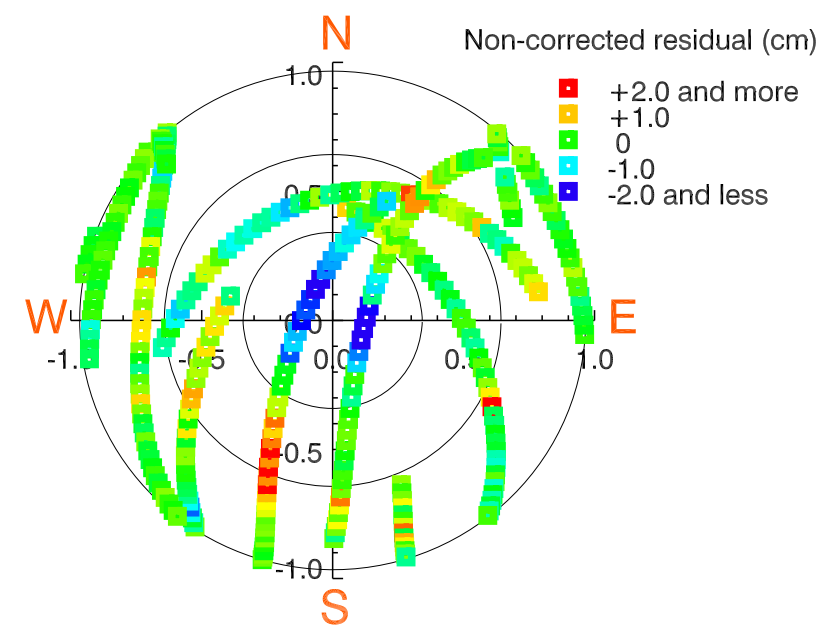

Fig. 15. The same as Fig. 13 except that the non-corrected residuals are plotted.

the residuals.

\subsection{Passages of the Baiu front}

We investigated the corrected residuals around the time of the passage of the Baiu front. Using a series of surface weather charts and surface meteorological observations, the Baiu front passed above Yamagawa toward the north at a velocity of about $15 \mathrm{~km} / \mathrm{h}$ around 2 UT on June 23, 1996, and stayed to the north, about $100 \mathrm{~km}$ away from Yamagawa. There were the following two characteristics of this event. First, no precipitation was observed at the Kagoshima meteorological observatory. Second, lower clouds, with a bottom height of less than $3.8 \mathrm{~km}$, were not detected around the period of the event except after 7:20 UT. This observation was from a ceilometer. Therefore, a change in the source of water vapor content mostly depended on inflow. For reference, 


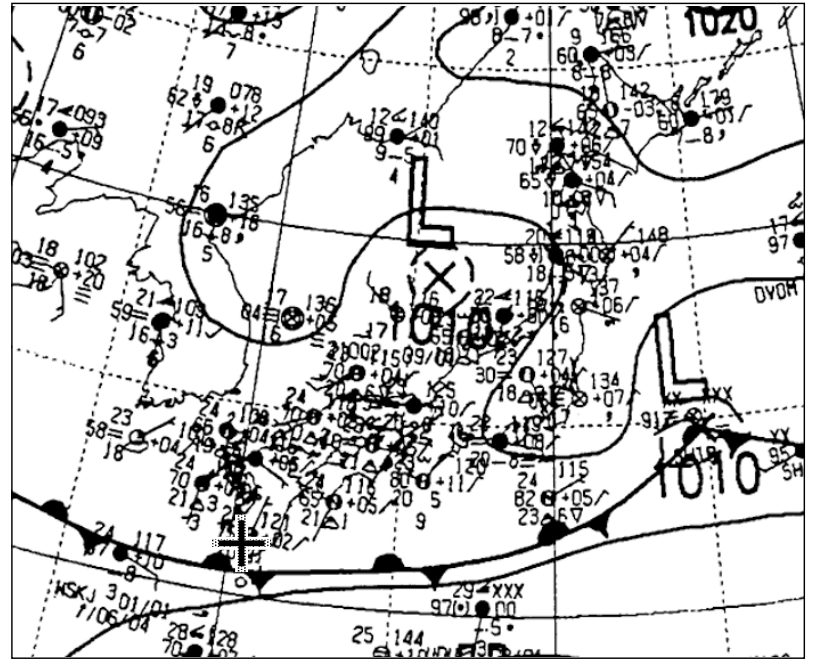

Fig. 16. The same as Fig. 10 except for the date and time, 0:00 UT on June 23, 1996.

Figs. 16 and 17 show a surface weather chart and a satellite cloud image, respectively.

As shown in Fig. 18, we selected the time window of 0-8 UT on June 23, 1996 to examine the variation of the corrected residuals with this event. In this figure, note that the values of the corrected residuals are larger in the south than in the north. Also note that the values of corrected residuals seem to vary continuously in the north-south direction. To more clearly display the changes shown in Fig. 18, we plotted the same results in Fig. 19 in the form of a time series. For example in this figure, the corrected residuals of the SV37-satellite, which moved from the north to the south in this period, linearly increase with time (i.e. toward the south direction). Therefore, it appears that the corrected residuals represent the fine structure of the Baiu front, which is more moist on it's south side.

\subsection{Consistency between the corrected residuals and} lower clouds

Next, we investigated more small-scale perturbations of the corrected residuals than discussed above. Here, we discuss consistency between the corrected residuals and lower clouds, whose bottom height of less than $3.8 \mathrm{~km}$ was observed from the ceilometer measurement with an original time resolution of $12 \mathrm{~s}$. Figure 20 shows the bottom height of the lower two cloud layers detected with a ceilometer on June 23. In this figure, it can be seen that a lower cloud layer was detected at an altitude of 300-500 m after 7:20 UT, although there were few clouds before then. Therefore, note that the clouds developed in the period from 7 to $8 \mathrm{UT}$. It is important how these clouds appeared above the observation site at this time. Therefore, we investigated the wind over the site by using the BLR data (In Fig. 21). From the BLR data, we can see that winds were blowing toward the east-northeast with a velocity of about $10 \mathrm{~m} / \mathrm{s}$ at an altitude of $300-500 \mathrm{~m}$ around 7-8 UT. In order to examine the corrected residuals during this period, we plotted them in Fig. 22. In this figure, note that the corrected residuals show a water vapor gradient decreasing to the north-

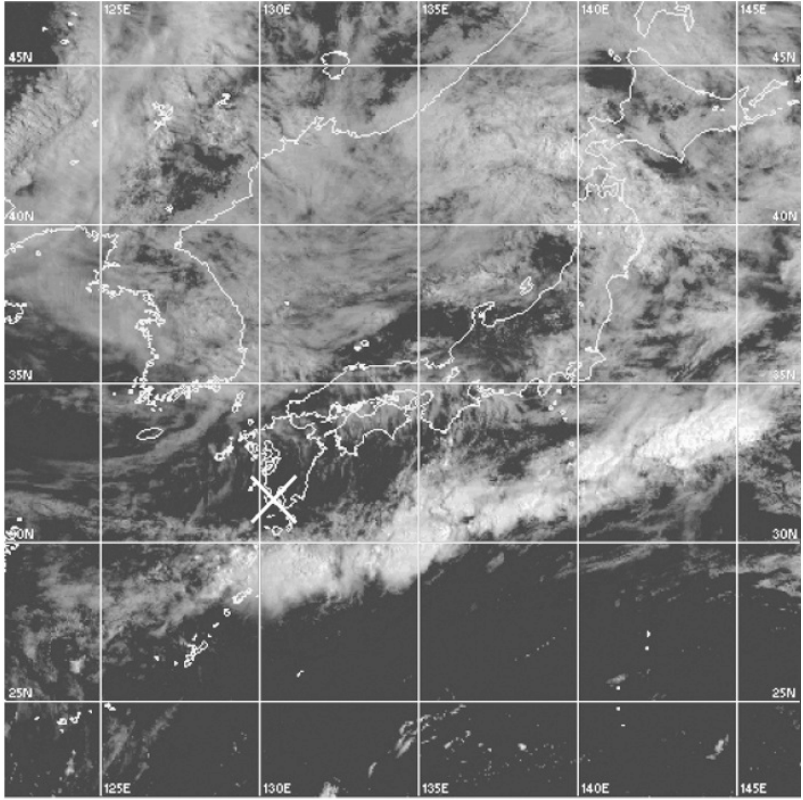

Fig. 17. The same as Fig. 11 except for a picture of visible rays and at 0:40 UT on June 23, 1996.

east or east-northeast. Based on the information discussed above, the corrected residuals were consistent with ceilometer and BLR measurements, suggesting increased water vapor in wind-driven lower clouds.

\subsection{Comparison among neighboring stations}

Finally, we investigated the consistency between the "nearest neighbor" stations in the Nagoya campaign to verify the applicability of this correction method where there are different types of antennas. As mentioned in Subsection 2.2, we selected four stations, $2 \mathrm{NGA}$ and $2 \mathrm{NGT}$, and $8 \mathrm{NGA}$ and 8 NGT. The elevation-angle-dependence calculated for each site was based on data taken over four days. Data for three days was used for station 2NGT because of problems with data acquisition.

In order to present the general trend of the weather during the campaign period, we plotted PWV's, which were obtained at site number 8, in Fig. 23. As mentioned in Subsection 2.2, a cold front passed above Nagoya around 15 UT on October 24. Therefore, we thought that there would be the greatest variation of the spatial water vapor distribution around this time in the campaign period.

Figure 24 shows the non-corrected residuals for two kinds of antenna, the Ashtech and Trimble (as previously mentioned) at site number 8 . We selected the period of 1723 UT November 23, in which a cold front passed above Nagoya. Although these two station were only a few meters away, changes in the non-corrected residuals were not the same. However, the corrected ones resembled one another very well, as shown in Fig. 25. In order to show the differences between them, we plotted the non-corrected and corrected residuals of the SV-16-GPS-satellite in the form of a time series for the four stations in Figs. 26 and 27, respectively. In Fig. 26, it is clear that the structure of the perturbation of the non-corrected residuals is more similar in comparison between the receivers of the same antenna type than 


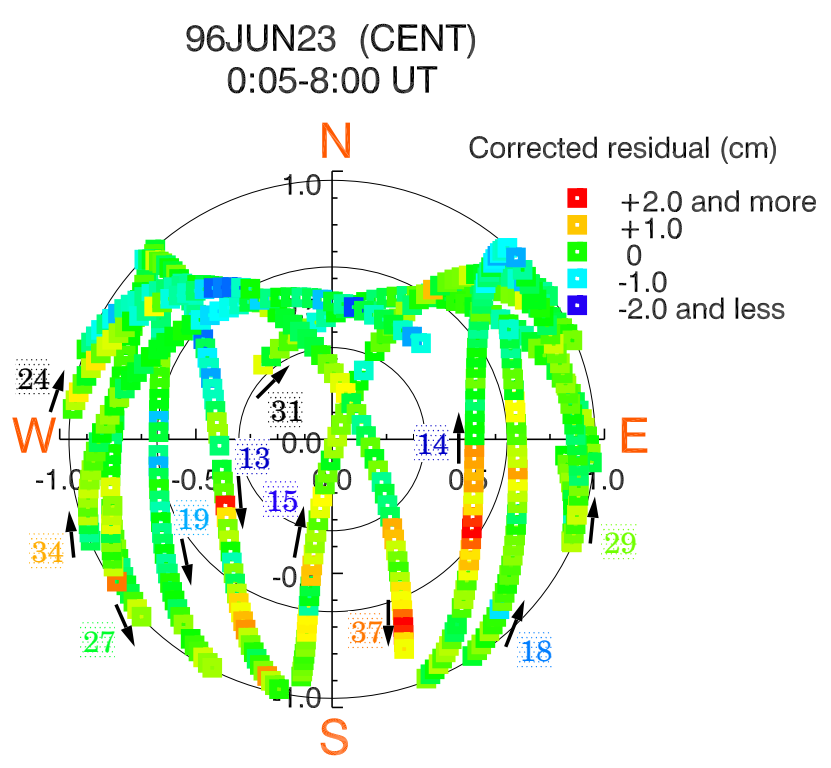

Fig. 18. The same as Fig. 12 except the time is $0-8$ UT on June 23. Note that the SV number of the satellites and their moving directions of them are shown for the main satellites in this period.

\section{Corrected residual of CENT Sta.} 96JUN23 0:05-8:00

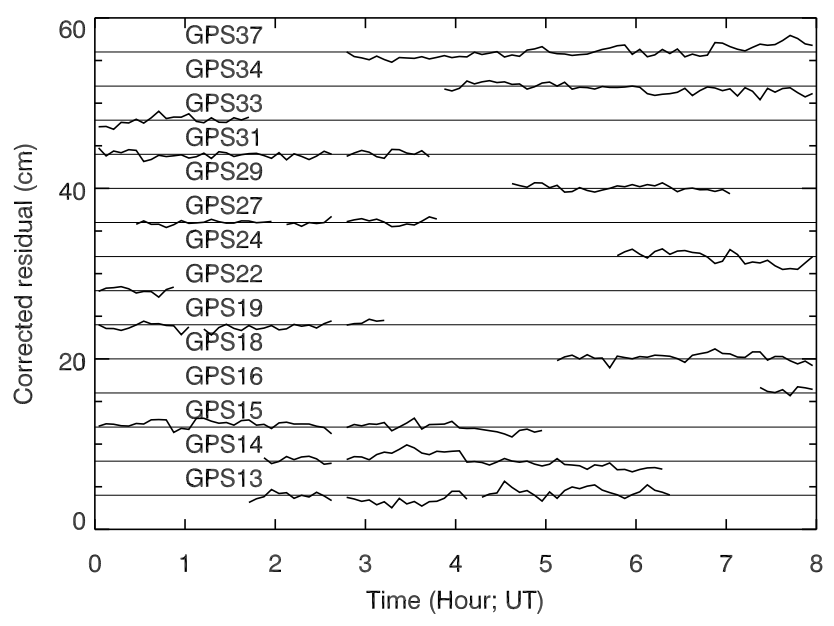

Fig. 19. The same as Fig. 18 except for represented in the form of time series.

between the closely located receivers. On the other hand, the structures of the corrected ones are very similar to one other. Therefore, the residuals were successfully corrected with this novel technique and the corrected ones seem to represent more realistic meteorological signals.

For a water vapor tomography, which is our ultimate purpose, it is very important to obtain differences in the real meteorological signals among observational stations from the residuals. However, differences in the corrected residuals were not clearly recognized from the results in Fig. 27. For this reason, we thought that the periods used for calculating elevation-angle dependencies were not sufficiently large to view meteorological signals as random signals because we were using three- or four-day observational data. There-

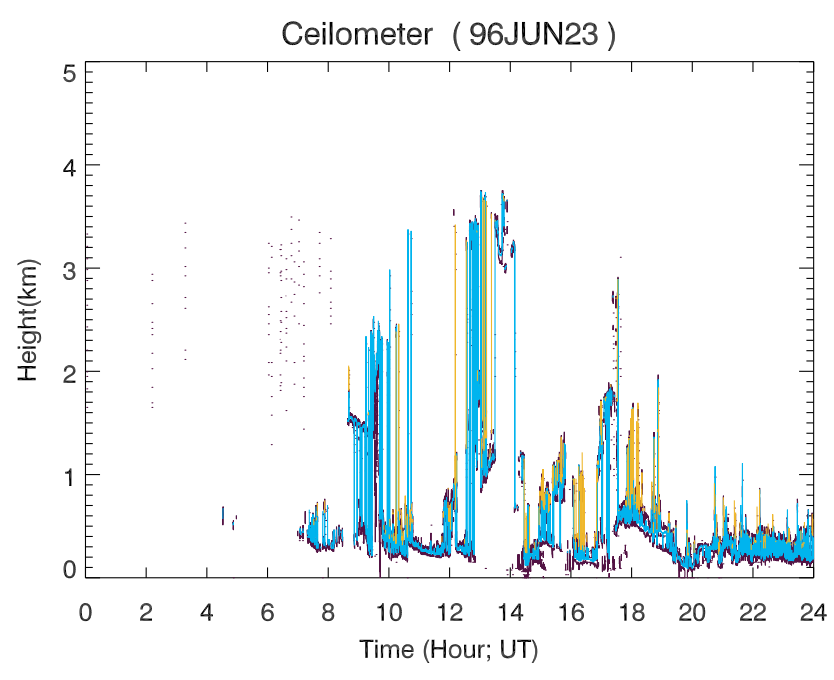

Fig. 20. The bottom height of the lower two clouds detected with a ceilometer on June 23, 1996. A blue and an orange line correspond to the lowest and second cloud, respectively.

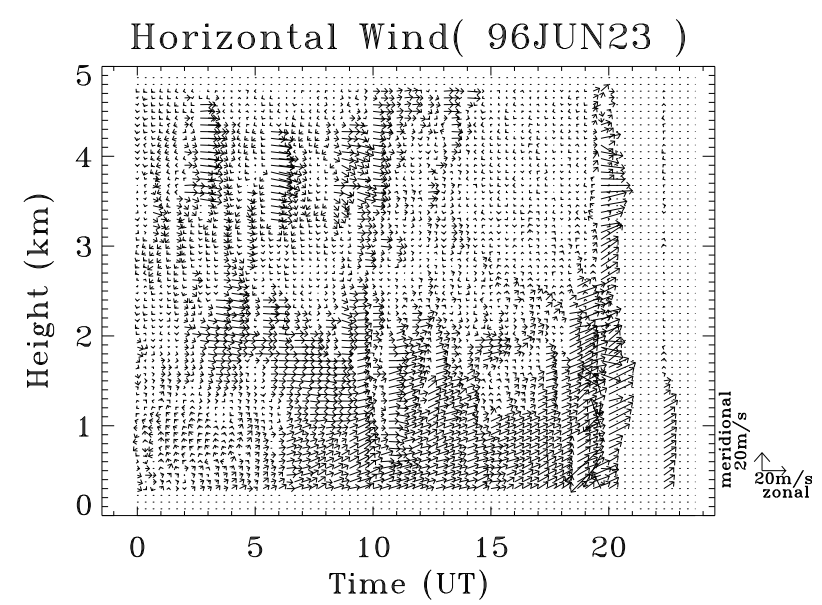

Fig. 21. Wind velocity and direction observed from BLR on June 23, 1996.

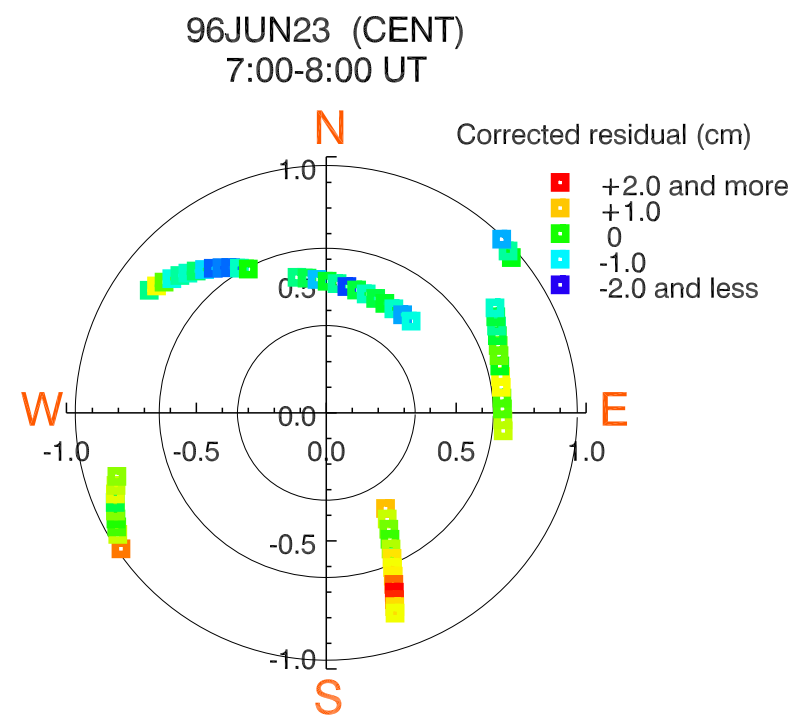

Fig. 22. The same as Fig. 12 except for the time, 7-8 UT on June 23, 1996. 


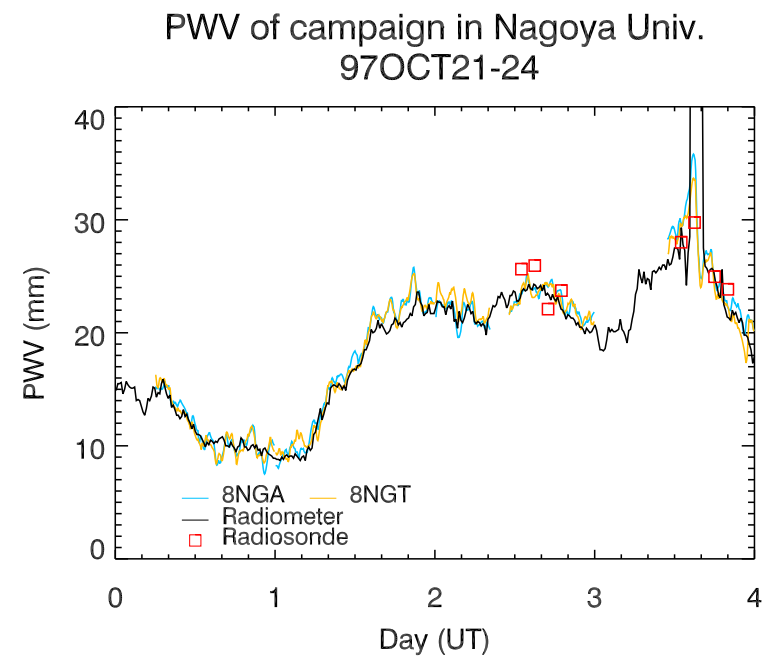

Fig. 23. PWV obtained from each measurement at observation site number 8 during October 21 and 24.
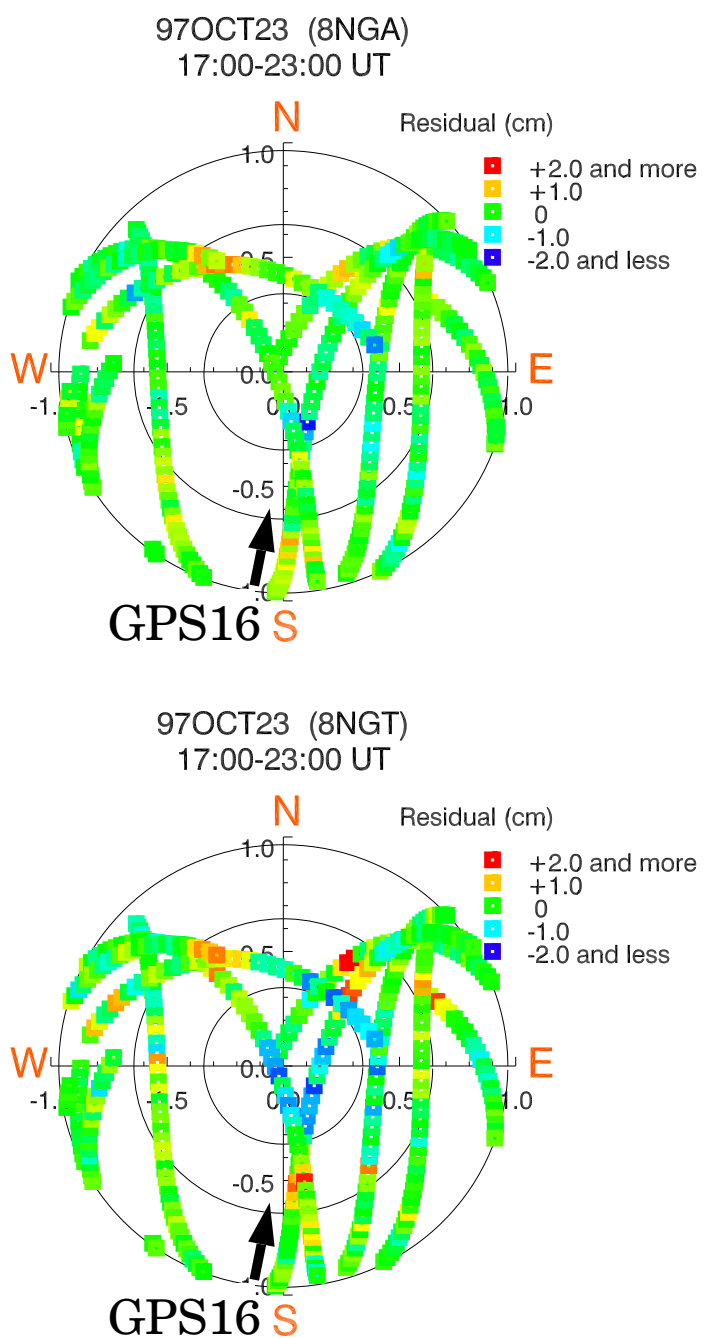

Fig. 24. Comparison of non-corrected residuals between 8 NGA and 8 NGT GPS stations, which were located within a few meters of each other, for the data taken during 17 and 23 UT on October 23, 1997. The arrow represents the moving direction of the SV-16-satellite. fore, we recommend using long-term observational data for calculating elevation-angle dependencies. Then, this correction will be very useful and more powerful for water vapor tomography.

\section{Summary}

We discussed in this paper the two important points concerning slant wet delay, in order to perform local water vapor tomography analysis. That is, we investigated the means to extract vapor effects from residuals and the accuracy of corrected residuals. Here, we summarize the main conclusions of this study.

1) The residuals, which were obtained directly from analysis with the GIPSY-OASIS II, were strongly dominated by dependence on elevation angle. The effects of a multipath and an antenna phase characteristic are contained within the analysis.

2) We successfully corrected the residuals by subtracting the elevation-angle-dependence, which was obtained as the mean residual for each satellite.

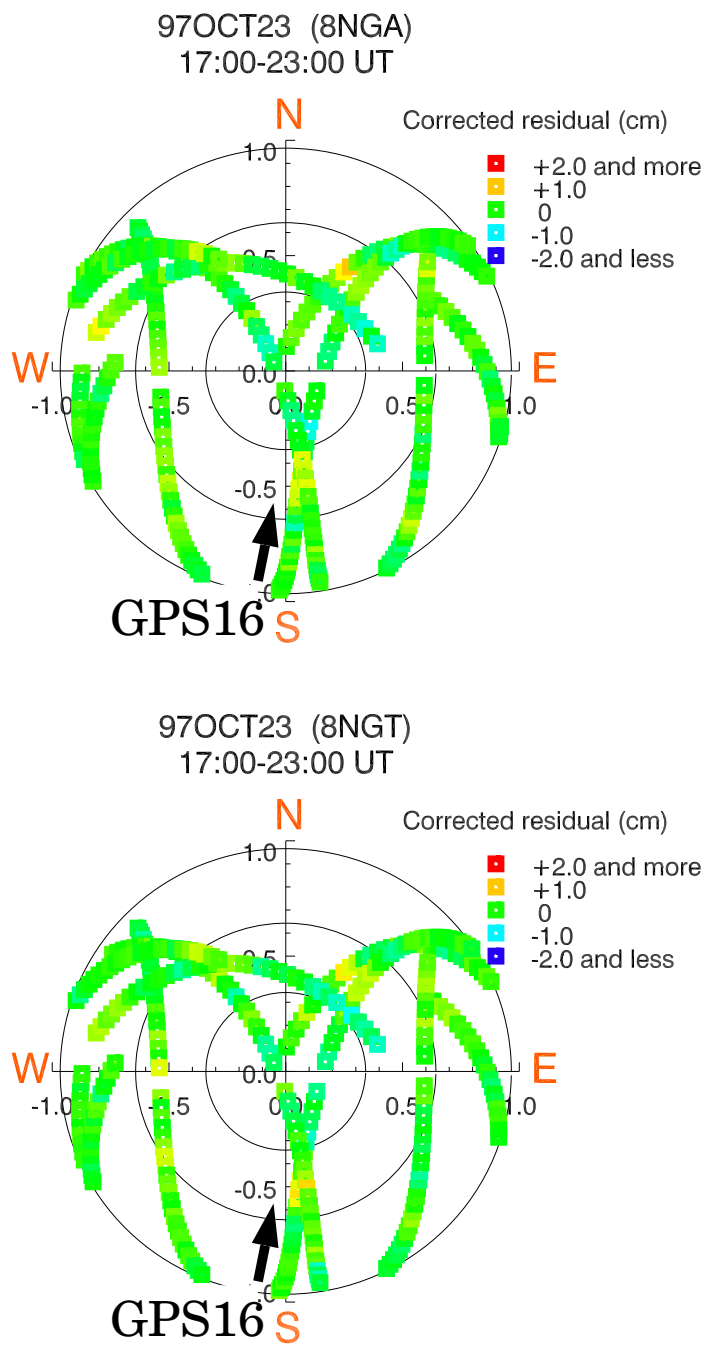

Fig. 25. The same as Fig. 24 except for the corrected residuals. 


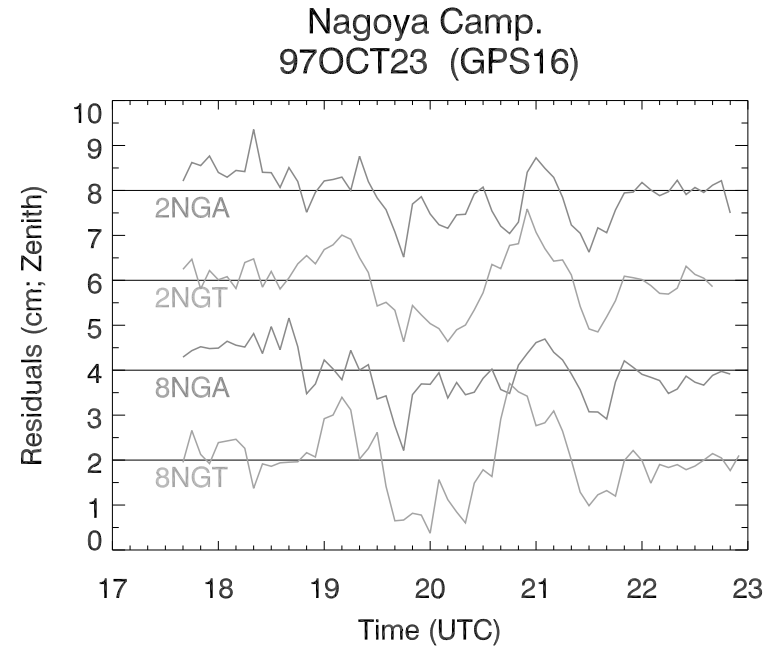

Fig. 26. Comparison of non-corrected residuals for SV-16-satellite and four GPS receivers during 17-23 UT on October 23, 1997.

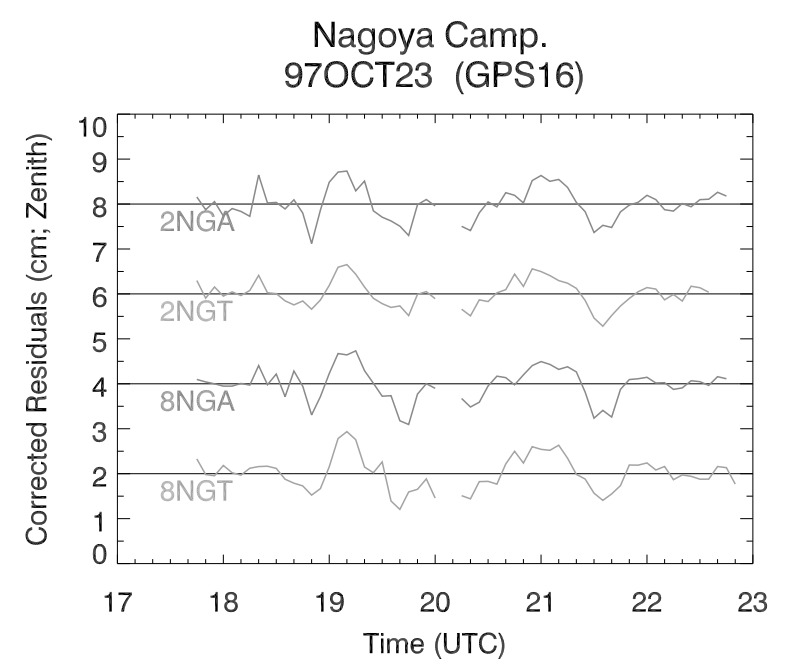

Fig. 27. The same as Fig. 26 except for the corrected residuals.

3) The water vapor distribution calculated from the corrected residuals showed realistic features that corresponded to frontal structures in two of four frontal events.

4) In comparing corrected residuals and inflow of lower clouds obtained from a ceilometer and BLR, both were consistent. Therefore, small-scale variations of residuals seem to correctly reflect actual changes in water vapor quantity.

5) In comparing the corrected residuals from four receivers located within about $790 \mathrm{~m}$, we found that the structures were very consistent regardless of the different antenna types.

From these results, we concluded that removal of the effects of a multipath and an antenna phase characteristic from the residuals is possible. As input data, the one-way residuals can provide reliable water vapor estimation, which can be used for water vapor tomography analysis. This tech- nique will contribute to the improvement of time resolution tomography analysis because of the appearance of noise contained in non-corrected residuals with shorter timeaveraging.

Acknowledgments. We are very grateful to Professor T. Tanaka of the Disaster Prevention Research Institute, Kyoto University, for his helpful advice, kind encouragement and for providing the various instruments for this study. We appreciate Dr. F. Kimata of the Graduate School of Science, Nagoya University, for his progressive advice and for providing the GPS campaign data set. We wish to express our hearty gratitude to Dr. T. Nakano for his instructive advice, kind encouragement and kindhearted help. We also greatly thank Dr. R. Otani for his constructive advice, useful suggestions and comments. We appreciate Professor I. Naito of the National Astronomical Observatory, for his kind advice and kindhearted encouragement in this study. We wish to express our thanks to Dr. S. Shimada of the National Research Institute for Earth Science and Disaster Prevention, for his helpful advice and kind encouragement. We are also thankful to Drs. H. Seko and Y. Syoji of the Meteorological Research Institute, for their kind advice, kindhearted encouragement and for providing the GMS5 and meteorological data. We wish to thank Drs. Y. Hatanaka and S. Miyazaki of the Geographical Survey Institute for their kind advice and encouragement, and for providing the GSI data. Thanks are also due to all staff and operators who took part in the Yamagawa Campaign. We are also thankful to all staff and operators who took part in Nagoya campaign. This study was supported by the Japanese GPS-Meteorology project of Science and Technology Agency (STA), Japan. The author was supported by a grant from the Japan Society for the Promotion of Science (JSPS) under the Fellowships for Japanese Junior Scientists.

\section{References}

Alber, C., R. Ware, C. Rocken, and F. Solheim, GPS surveying with $1 \mathrm{~mm}$ precision using corrections for atmospheric slant path delay, Geophys. Res. Lett., 24, 1859-1862, 1997.

Askne, J. and H. Nordius, Estimation of tropospheric delay for microwaves from surface weather data, Radio Sci., 22, 379-386, 1987.

Bevis, M., S. Businger, T. A. Herring, C. Rocken, R. A. Anthes, and R. H. Ware, GPS Meteorology: Remote sensing of atmospheric water vapor using the Global Positioning System, J. Geophys. Res., 97, 1578715801, 1992.

Duan, J., M. Bevis, P. Fang, Y. Bock, S. Chiswell, S. Businger, C. Rocken, F. Solheim, T. VanHove, R. Ware, S. McClusky, T. Herring, and R. King, GPS Meteorology: Direct estimation of the Absolute value of precipitable water, J. Appl. Met., 35, 830-838, 1996.

Elósegui, J., J. L. Davis, R. T. K. Jaldehag, J. M. Johansson, A. R. Niell, and I. I. Shapiro, Geodesy using the Global Positioning System: The effects of signal scattering on estimates of site position, J. Geophys. Res., 100, 9921-9934, 1995.

Hopfield, H. S., Two-quartic tropospheric refractivity profile for correcting satellite data, J. Geophys. Res., 74, 4487-4499, 1969.

Imakiire, T., Y. Iimura, S. Saga, H. Morishita, A. Tsuchiya, F. Kudo, S. Ishikawa, and Y. Iwana, Results of phase characteristics measurements of GPS receiver antennas (2), J. Geod. Soc. Japan, 43, 79-90, 1997.

Iwabuchi, T., I. Naito, S. Miyazaki, and N. Mannnoji, Precipitable water vapor moved along a front observed by the Nationwide GPS Network of Geographical Survay Institute, TENKI, 44, 767-784, 1997.

Meertens, C., C. Alber, J. Braun, C. Rocken, B. Stephens, R. Ware, M. Exner and P. Kolesnikoff, Field and anechoic chamber test of GPS antennas, IGS 1996 analysis center workshop proceedings, 107-118, 1996.

Tsuji, H., K. Sugita, K. Nemoto, S. Mashiko, K. Goto, M. Iwata, M. Murakami, I. Otsu, S. Ishikawa, and A. Tsuchiya, Results of phase characteristic measurement of GPS receiver antennas, J. Geod. Soc. Japan, 39, 179-192, 1993.

Ware, R., C. Alber, C. Rocken, and F. Solheim, Sensing integrated water vapor along GPS ray paths, Geophys. Res. Lett., 24, 417-420, 1997.

T. Yoshihara (e-mail: yosihara@kurasc.kyoto-u.ac.jp), T. Tsuda, and K. Hirahara 